\title{
THE ARTIFICIAL INDUCTION OF SUBCUTANEOUS NODULES IN PATIENTS WITH RHEUMATIC FEVER ${ }^{1}$
}

\author{
By BENEDICT F. MASSELL, JOHN R. MOTE, AND T. DUCKETT JONES \\ (From the House of the Good Samaritan, Boston)
}

(Received for publication September 21, 1936)

Although subcutaneous nodules in subjects with rheumatic fever were described prior to the report of Barlow and Warner (1), these workers presented the first series of observations on 27 patients and described the clinical characteristics of nodules. Like Cheadle (2), these observers believed subcutaneous nodules to be diagnostic of rheumatic fever. The early literature has been adequately summarized by Futcher (3), and McEwen (4) has recently reviewed the more recent reports.

Subcutaneous nodules are usually multiple and may appear in crops over the bony prominences and sometimes on tendons. They are painless, non-tender, vary considerably in both size and consistency, and may be present from a few days to several months. Nodules are most apt to occur in patients with the more severe forms of rheumatic heart disease and many observers consider them to indicate a grave prognosis.

Drewitt (5) first hypothesized that trauma was involved in the production of subcutaneous nodules because of their common occurrence over bony prominences. In confirming the many observations on the location of subcutaneous nodules, we were impressed with the possibility that trauma may be a factor in their appearance. Interest in such a probability resulted in an attempt to traumatize the elbows of rheumatic fever subjects by several methods to see if subcutaneous nodules could be artificially induced. The results of these attempts to reproduce subcutaneous nodules form the basis of the present report.

\section{CLINICAL MATERIAL}

The present report is based on studies upon 116 patients who are divided into the following groups:

(1) Sixty patients had rheumatic fever, exclusive of those with chorea. Twenty had clin-

1 The expenses of this study have been defrayed by a grant from the Commonwealth Fund. ical manifestations of the disease, twenty-six were convalescing from clinical rheumatic fever but at the time of observation had only laboratory evidence of infection (i.e., an elevated sedimentation rate, leukocytosis, or prolongation of auriculoventricular conduction time by electrocardiogram), and fourteen were convalescing from rheumatic fever but at the time studied exhibited no clinical or laboratory evidence of active disease.

(2) Twenty-two patients had active or subsiding chorea as their presenting sign. Six of these had rheumatic heart disease, one had congenital heart disease, and in fifteen there was no clinical evidence of cardiac involvement. Six had chorea as their only manifestation of rheumatic fever, and sixteen had other symptoms of rheumatic fever in the past or at the time of the test. At the time of the study the degree of chorea varied from minimal to moderate.

(3) Thirty-four subjects with diseases other than rheumatic fever. were used as controls. Thirty of these had bone tuberculosis of varying severity, one had hysteria, one habit spasm, one was convalescing from pneumonia, and one had subacute bacterial endocarditis.

The ages of the subjects composing these three groups were comparable, averaging 10 years and ranging between 4 and 16 years.

\section{METHODS}

The chief method of approach in our attempt to induce the formation of nodules, and that used on each of the 116 patients of this series, was as follows.

The region of the olecranon process was infiltrated with $1 \mathrm{cc}$. of 1 per cent novocaine. From the antecubital vein of the opposite arm 2 to $3 \mathrm{cc}$. of blood was removed and immediately injected into the subcutaneous and deep tissues of the anesthetized area. During the next ten days, frictional pressure was applied by having the patient rub the injected elbow on the bedclothes for 
several minutes (or until the skin became warm), six times a day.

In addition to this primary method, the following procedures were used.

(1) Five subjects had one elbow tested in the above mentioned manner, and the other elbow injected only with novocaine before frictional pressure was applied.

(2) Fifteen patients tested by the primary method had only frictional pressure to the other elbow.

(3) Nine patients were injected by the basic method over both elbows, but frictional pressure was applied to only one elbow.

(4) Finally, twenty patients had normal saline substituted for blood in injecting the other elbow.

\section{RESULTS}

A hematoma developed over the elbow in those cases in which blood was injected. In some individuals the diffuse subcutaneous thickening subsided, and the tissues regained their normal texture by the end of one to two weeks. In others, as the hematoma subsided there appeared, usually by the end of the first or during the second week, a discrete, moveable, subcutaneous nodule-like structure. In the beginning, this was poorly defined and somewhat soft, but usually within another week or more it became definitely circumscribed and firm. The size varied from about 2 to $10 \mathrm{~mm}$. in diameter. Clinically, these induced nodules could not be distinguished from the subcutaneous nodules which appear spontaneously in patients with rheumatic fever.

Table I summarizes the results of these experiments involving the subcutaneous injection of blood in 116 individuals.

Of twenty patients with clinical rheumatic fever, eighteen ( 90 per. cent) developed nodules at the site of injection, and two-thirds were of moderate size or larger.

Of twenty-six patients with only laboratory evidence of active rheumatic fever, thirteen (50 per cent) exhibited a nodule response. Five of the nodules were of moderate to large size, and eight were small but definite.

Of fourteen patients without clinical or laboratory evidence of active infection, only two (14
TABLE I

Distribution and size of induced nodules

\begin{tabular}{|c|c|c|c|c|c|c|c|}
\hline \multirow{2}{*}{ Group } & \multirow{2}{*}{ 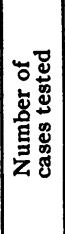 } & \multicolumn{2}{|c|}{$\begin{array}{c}\text { Successful } \\
\text { nodule } \\
\text { reaction }\end{array}$} & \multicolumn{2}{|c|}{$\begin{array}{c}\text { No } \\
\text { nodule } \\
\text { reaction }\end{array}$} & \multicolumn{2}{|c|}{$\begin{array}{l}\text { Size of } \\
\text { induced } \\
\text { nodules }\end{array}$} \\
\hline & & $\begin{array}{l}\text { 岁 } \\
\text { 莺 }\end{array}$ & 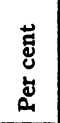 & 䓌 & 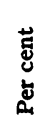 & चึ & 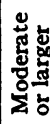 \\
\hline 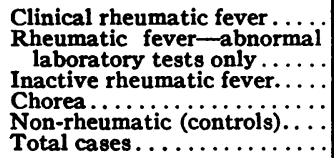 & $\begin{array}{r}20 \\
26 \\
14 \\
22 \\
34 \\
116\end{array}$ & $\begin{array}{r}18 \\
13 \\
2 \\
3 \\
1 \\
37\end{array}$ & $\begin{array}{l}90 \\
50 \\
14 \\
14 \\
3 \\
32\end{array}$ & $\begin{array}{r}2 \\
13 \\
12 \\
19 \\
33 \\
79\end{array}$ & $\begin{array}{l}10 \\
50 \\
86 \\
86 \\
97 \\
68\end{array}$ & $\begin{array}{r}6 \\
8 \\
2 \\
3 \\
1 \\
20\end{array}$ & $\begin{array}{r}12 \\
5 \\
0 \\
0 \\
0 \\
17\end{array}$ \\
\hline
\end{tabular}

per cent) developed nodules, and in both instances they were of small size.

The twenty-two patients with chorea as their presenting symptom have been classified separately. Only three subjects (14 per cent) developed nodules, and in each instance the nodule was of small size. One had laboratory evidence of active rheumatic fever. The second was convalescent from frank rheumatic fever, but at the time of injection had no clinical or laboratory evidence of activity. The third had chorea as the only known manifestation of rheumatic fever.

Of the thirty-four control patients, one ( 3 per cent) developed a definite nodule. This patient had low-grade fever, which may be explained by his active bone tuberculosis. However, in the past, he had spontaneous nosebleeds, and on examination there was a question as to the presence of an early aortic diastolic murmur. No definite diagnosis of rheumatic fever could be made.

These results apply only to those instances in which blood was injected subcutaneously into an anesthetized area overlying the olecranon process and the elbow then rubbed so as to produce frictional pressure. The results of the four additional procedures are also of interest and follow.

Four of five rheumatic patients who had blood injected by the basic method developed nodules after the maneuver, while the injection of novocaine alone into the other elbow and subsequent frictional pressure failed to cause a nodule response in any instance.

None of the fifteen patients who had only frictional pressure applied to one elbow developed nodules, but six of these same patients exhibited 
a nodule response on the elbow where blood was injected.

Nine patients had blood injected subcutaneously into both elbows with frictional pressure to one elbow only. Five developed nodules bilaterally, while four had no reaction over either elbow.

Twenty individuals were injected with blood in one elbow and saline in the other. Six developed nodules at the sites of blood injection, and in four of these, nodules resulted also over the elbow, injected with saline.

\section{DISCUSSION}

It has been demonstrated that the injection of blood subcutaneously over the anesthetized olecranon process with subsequent frictional pressure resulted in the appearance of a nodule in the injected area in 37 ( 45 per cent) of 82 subjects with rheumatic fever and chorea. In no instance was friction alone a sufficient stimulus to induce the formation of a nodule. Nodules did appear over the areas where blood was injected, and in which there was no subsequent frictional pressure. Nodules did not appear as the result of infiltration with small amounts of novocaine.

From the evidence available it seems possible that tissue injury, if sufficient, may be of primary importance, although blood as a stimulant in itself cannot be ruled out. Of six individuals in whom the injection of blood induced nodules four had nodules appear also over the elbows in which saline was substituted for blood. The injection of 2 to $3 \mathrm{cc}$. of saline subcutaneously is necessarily accompanied by bleeding. At this time it would be mere speculation to make definite implications with regard to the actual process whereby these nodules appear.

In the rheumatic fever subjects injected, these induced nodules were definitely related to the activity of the rheumatic fever process. The appearance of nodules in 90 per cent of those patients with clinically active rheumatic fever, and in 50 per cent of those with only laboratory evidence of active rheumatic fever (67 per cent of the combined groups), was in striking contrast to their appearance in only 14 per cent of rheumatic fever subjects without evidence of active rheumatic fever, and in 14 per cent of those sub- jects with chorea. From the above, it was evident that these induced nodules occurred more frequently in the patient with active rheumatic fever, as is the case with spontaneous nodules.

The size of the induced nodules also varied to some extent with the degree of activity of rheumatic fever. Thus, in the group with clinical rheumatic fever, two-thirds of the nodules were of moderate size or larger, while slightly less than one-half were of this size in the group with only laboratory evidence of active rheumatic fever. In the subjects with inactive rheumatic fever and chorea, all induced nodules were small.

Similarly, the duration of the induced nodules varied from a few weeks to several months, lasting the relatively longer periods in those individuals who had persistent infection. Their clinical course was hence comparable to the nodules observed to occur spontaneously in subjects with rheumatic fever.

These facts suggest a clinical similarity to spontaneous nodules.

A nodule appeared in only one ( 3 per cent) of the 34 control subjects, and the possibility has been mentioned that this child may be suffering from rheumatic fever. More adequate control studies are necessary before definite conclusions may be reached concerning the specificity and significance of these induced nodules. Therefore, it is not possible at this time to suggest that the induction of such nodules could be used as a diagnostic test of the presence or absence of rheumatic fever.

The histopathology of these induced nodules, and their comparison with spontaneous nodules will form the basis of the succeeding report (6).

\section{SUM MARY}

(1) The injection of the patients' own blood into the subcutaneous tissues of subjects with rheumatic fever frequently results in the appearance of subcutaneous nodules in the area injected. They are clinically indistinguishable from nodules occurring spontaneously.

(2) The same procedure carried out in thirtyfour presumably non-rheumatic individuals resulted in nodule formation in a single instance.

The authors wish to express their appreciation to Mrs. Nellie S. Smith and to Dr. Gerald N. Hoeffel of the New 
England Peabody Home for Crippled Children, who have made possible control studies.

\section{BIBLIOGRAPHY}

1. Barlow, T., and Warner, F., On subcutaneous nodules connected with fibrous structures occurring in children the subjects of rheumatism. Tr. Internat. M. Cong., 7th session, London, 1881, 4, 116.

2. Cheadle, W. B., Various manifestations of the rheumatic state as exemplified in childhood and early life. Lancet, 1889, 1, 871.
3. Futcher, T. B., A study of subcutaneous fibroid nodules. Bull. Johns Hopkins Hosp., 1895, 6, 133.

4. McEwen, C., Cytologic studies on rheumatic fever. I. The characteristic cell of the rheumatic granuloma. J. Exper. Med., 1932, 55, 745.

5. Drewitt, F. D., Pathological Society of London. Communications on rheumatic nodules. Brit. M. J., 1883, 1, 622.

6. Mote, J. R., Massell, B. F., and Jones, T. D., The pathology of spontaneous and induced subcutaneous nodules in rheumatic fever. J. Clin. Invest., 1937, $16,129$. 